\title{
La participación a través de los diálogos de Platón
}

«Un estudio del pensamiento de Platón, dice Julián Marías, tendrá que ser forzosamente una peregrinatio ad fontes, un intento de conjurar a Platón e invocarlo en sus propias palabras, valiéndose de ellas, literalmente «tomándolo por la palabra» '.

El título de este trabajo parece exigir que ordenemos cronológica y doctrinalmente la obra platónica, y que señalemos después la orientación a seguir en esta "peregrinatio» "a través» de las bellas construcciones del autor de $\mathrm{La}$ República.

La cuestión del orden cronológico-doctrinal de los diálogos podría construir por sí todo un edificio de bibliografía $y$ de trabajos especializados. Nosotros solamente vamos a recordar algunas de las clasificaciones hechas por los especialistas, que han estudiado a fondo la producción del «divino» filósofo.

Centraremos nuestra atención en el sentido de la participación platónica.

Según Tovar, «el Sofista fue escrito tarde, y figura entre los diálogos de Platón que suelen rechazar los lectores superficiales y apresurados. Debió ser redactado, desde luego, por los años en que Platón sé ha desengañado en su intento de imponer orden filosófico en el gobierno de Dionisio el Joven. Ha regresado de su segundo viaje a Siracusa. Piensa en completar una trilogía el Sofista, el Político, el Filósofo, cuyo prólogo es, clausurando el segundo período el Teeteto, obra destructiva, de transición, en la que la doctrina de la verdad y de la contradicción quedan en tela de juicio. Según las deducciones más verosímiles se escribió hacia 365 , en todo caso antes de 361 , fecha del tercer viaje de Platón a Siracusa. Los análisis estilísticos confirman estas fechas: el orden Parménides, Sofista, Político, Filebo, Timeo, Leyes, es admitido invariablemente por los clásicos del método: Lutoslawsky, Gomperz, Natorp, Raeder y Ritter» ${ }^{2}$.

1. ARISTÓTELES, Ética a Nicómaco. Introducción y notas de J. Marías. Texto bilingüe. Instituto de Estudios Politicos. Madrid 1959, IX.

2. A. TOVAR, Introducción a PLATÓN, El Sofista. Texto bilingüe. Instituto de Estudios Políticos. Madrid 1970, V. 

biendo sido el primero que aplicó el pensamiento a las definiciones, (Platón) aceptó sus enseñanzas, pero por aquel motivo pensó que éste se producía en otras cosas, y no en las sensibles; pues le parecía imposible que la definición común fuese de alguna de las cosas sensibles, al menos de las sujetas a perpetuo cambio. Éste, pues, llamó a tales entes Ideas, añadiendo que las cosas sensibles están fuera de ellas, pero según éstas se denominan todas; pues por participación tienen las cosas que son muchas el mismo nombre que las Especies. $Y$, en cuanto a la participación, no hizo más que cambiar el nombre; pues los pitagóricos dicen que los entes son por imitación de los números, y Platón, que son por participación, habiendo cambiado el nombre» ${ }^{4}$.

El reactivo del diálogo platónico es la opinión fallida, ya que al formularse se revela como insostenible y por ló mismo es necesario ir a la búsqueda de otra más apropiada. Desde la opinión se impone el camino hacia la episteme, lugar estable y apropiado para la formación científica.

La teoría platónica de las ideas es también una teoría de las consistencias. A diferencia de Parménides, Platón no se queda en las consistencias, sino que vuelve hacia las cosas intentando comprenderlas y dominarlas. La diąléctica platónica busca a través de las ideas el camino hacia lo real.

En el Sofista Platón nos advierte de la importancia de la participación: "-Ext. Supongamos que ellos dicen, si quieres, primero que nada tiene ninguna posibilidad de participar en manera alguna de nada. ¿No sucedería que el movimiento y la quietud no participarían en modo alguno del ser?

- Tee. Pues no participarían.

- Ext. Pues con esta conclusión inmediatamente todo queda destruido, según parece, lo mismo lo que sostienen los partidarios de que todo se mueve a los que lo inmovilizan como unidad, que lo que los de que todos los seres en sus respectivas formas están quietos e idénticos siempre, pues todos atribuyen el ser, los unos diciendo que esencialmente las cosas se mueven, los otros que esencialmente están quietas $»^{5}$.

La participación, por tanto, parece un concepto clave dentro de la ontología del autor del Parménides; por la participación se pueden dar y se pueden entender las cosas que están en movimiento y la que no, y sin la participación no se puede producir, ni explicar la ciencia.

Ext.' «Entonces, que el movimiento es lo mismo y no es lo mismo, hay que reconocerlo y no hay que tomarlo a mal. Porque cuando digamos que áquel es lo mismo y no es lo mismo no decimos cosa semejante, sino que cuando decimos que es lo mismo, lo decimos por la participación del 'mismo respecto de sí mismo, y cuando decimos que no es lo mismo, lo decimos a su vez por la participación que tiene en lo otro, de manera que, por el contrario, también se dice rectamente que no es lo mismo» ${ }^{6}$.

4. ARISTÓTELES, Metafisica. Texto trilingüe de V. Garcla. Gredos, Madrid 1970, Libro I (A), $387 \mathrm{a-b}$.

5. PLATÓN, El Sofista. Instituto de Estudios Políticos. Madrid 1970, 251e-252a.

6. PLATÓN, El Sofista. Instituto de Estudios Políticos. Madrid 1970, 256 a-b. 
Algunos autores consideran que el Sofista es una especie de complemento del Parménides. Nosotros consideramos que, concretamente, la doctrina de la participación tiene amplias bases en La República y en el Parménides, pero que tiene su culminación en el Sofista - diálogo difícil y desconcertante-.

El ser es, sin duda, el caballo de batalla de una concepción filosófica. La Historia de la filosofía ha reflejado diversas opiniones sobre el ser. Para unos se subdivide en múltiples seres o entes, para otros también pluralistas hay algunos seres que se asocian para formar el ser. En estos casos, lo que el pluralismo no suele explicar es la unidad del ser; es decir, que cada uno de estos existentes sea y que participe de una unidad superior. Si admitiéramos la tesis de que el ser es el Uno y el Todo, parecería que se incluyen todas las diferencias o que se excluyen, pero también esta concepción es problemática. Platón parece que quiere dar a entender que en el Sofista aclara las objeciones que se había formulado en el Parménides, y que no eran tan graves como podría parecer. Es necesario replantear el problema del ser. Se ha dicho que el movimiento y el reposo participan de alguna forma en el ser. La «mentira» que es el fundamento de la enseñanza del sofista, ha mostrado que el no ser había de ser él mismo en cierto modo. De esta manera cae por tierra la tesis de Parménides que niega toda multiplicidad y que, así, impide que se hagan otros juicios que no sean tautológicos: el ser es.

Sobre la relación que puedan tener las esencias unas con otras, se ofrecen tres posibilidades: $O$ nada tiene poder de comunicarse con alguien, o todas las cosas tienen poder de comunicarse entre sí, o bien algunas esencias admiten mezclarse con otras y sólo con éstas.

La primera posibilidad conduce a una actitud contradictoria: Hablamos de la palabra «es», del vocablo «separadamente», del término «los otros», para que el hablar tenga sentido será necesario que las esencias se comuniquen.

La segunda conduce al hombre a un discurso vacío y sin sentido, o al silencio, si seguimos el consejo de Wittgenstein: "De lo que no se puede hablar, mejor es callarse»?.

Parece que en estas dos posibilidades primeras es difícil mantenerse y que hay que dirigirse hacia una tercera: Las Esencias se refieren las unas a las otras y se organizan, según conveniencias e inconveniencias, lo mismo que las sílabas se organizan para formar palabras y las palabras para formar proposiciones coherentes. El descubrir sus articulaciones o sus inconveniencias será tarea del lógico o del dialéctico.

El Ser, género supremo, es de lo que participan el movimiento y el reposo. Pues si una de estas determinaciones le faltara ya no sería el ser, pues no sería el Todo, no podría reunir el conjunto de calificaciones que hacen de él el ser mismo, la unidad sinténtica, o lo que Robin llama «la mezcla sintética».

7. L. WITTGENSTEIN, Tractotus Logico-Philosophicus. Texto bilingüe. Traducción de E. Tierno Galván. Alianza, Madrid 1973, 203, n. ${ }^{\circ} 7$. 
Heráclito y Parménides quedan superados, a la espera del Hilemorfismo; la estabilidad y el cambio son modos del ser. El ser es, siendo al mismo tiempo manantial de vida, fuente de participación. Platón aceptó el reto de que las cosas sensibles propiamente no tienen consistencia, pero frente a la inconsistencia de la realidad sensible, afirmó que la consistencia estaba en la idea. Para Rábade, uprecisamente en este desplazamiento de la verdad desde las cosas hasta el entendimiento es donde surge la necesidad de introducir un nuevo elemento en la concepción de la verdad, que es la orzotes. Si ya la verdad no consiste sin más en la presentación o desvelación de las cosas, sino que, por parte de éstas, consiste en la participación de la idea correspondiente o en la posesión de su morfé natural, y, por parte de mi entendimiento, en la captación de esa efectiva participación o posesión, es preciso restringir la denominación de verdad a aquellas cosas constituidas rectamente de acuerdo con su idea o con su forma» ${ }^{8}$.

En La República, Platón tras exponer el sentido de la justicia, la imagen de la ciudad ideal, la educación, la función del filósofo, pasa a estudiar en profundidad su teoría del ser y de la participación. Para llevar a cabo esta empresa utiliza material propiamente aclarativo-demostrativo, imágenes, mitos, alegorías.

Vamos a examinar enseguida algunos textos tomados de La República y relativos a la participación.

- «Puedes decir, por tanto, que lo que proporciona la verdad a los objetos del conocimiento y la facultad de conocer al que conoce, es la idea de bien, a la cual debes concebir como objeto de conocimiento, pero también como causa de la ciencia y de la verdad; y así por muy hermosas que sean ambas cosas, el conocimiento y la verdad, juzgarás rectamente si consideras esa idea como otra cosa distinta y más hermosa todavía que ellas. Y en cuanto al conocimiento y la verdad, del mismo modo que en aquel otro mundo se puede creer que la luz y la visión se parecen al sol, pero no que sean el mismo sol, del mismo modo en éste es acertado el considerar que uno y otra son semejantes al bien, pero no lo es el tener a uno de los dos por el bien mismo, pues mucho mayor (es) todavia la consideración que se debe a la naturaleza del bien $)^{9}$.

El bien está en la cúspide del sistema de Platón y de él participan todas las ideas. Es la causa de la ciencia y de la verdad. La verdad está en la idea suprema de Bien y las ideas verdaderas son tales, en cuanto que participan de esta verdad. Así pues, la verdad no está en las cosas, sino en el eidos, creándose así la metafísica como lo que está subsistiendo consistentemente más allá de la fisis. El bien tiene mayor consideración para Platón que la verdad y el cono-

8. S. RABADE ROMEO, Verdad, conocimiento y ser. Madrid 1974, 2.", 18.

9. PLATÓN, La República. Texto bilingüe. Instituto de Estudios Pollticos. Madrid 1969, 508 d-e, 509 a, Libro VI (S). 
cimiento, pues siendo bella la verdad y siendo bello el conocimiento, lo son por participación en el Bien y no debemos de identificarlos con el Bien.

El texto anterior y el que citamos - tomado del Mito de la Caverna- nos parecen centrales en la doctrina de la participación.

Esquema geométrico para explicar la teoría platónica sobre el ser:

$$
\frac{A D}{D B}==\frac{A C}{C D}==\frac{D E}{E B}
$$
A,
C,
D,
$E$, B，

AC representa las copias. Las copias, dice Platón, son primeramente las sombras trasladadas, $y$ en segundo lugar, las imágenes reflejadas en la superficie del agua, y también en los cuerpos que sean compactos, lisos y luminosos. CD representa «los animales que en nuestra experiencia conocemos $y$, en conjunto, todo lo que se procrea y lo que se fabrica. $A D$ constituye la sección de lo que es visible: el mundo sensible que percibimos. DB es el mundo de lo inteligible». Pero se puede dividir de forma semejante al mundo de lo sensible: "De modo que el alma se vea obligada a buscar la una de las partes sirviéndose, como de imágenes, de aquellas cosas que antes eran imitadas, partiendo de hipótesis y encaminándose así, no hacia el principio, sino hacia la conclusión; y la segunda, partiendo también de una hipótesis, pero para llegar a un principio no hipotético y llevando a cabo su investigación con la ayuda sola de las ideas tomadas en sí mismas y sin valerse de las imágenes que en la búsqueda de aquello recurría $)^{10}$.

El empeño de construir la filosofía more geométrico parece que tuvo en Platón y concretamente en el Libro sexto de La República un máximo exponente. Parece que la consigna colocada a la entrada de la academia platónica «no entre aquí quien no sepa geometría» debe de considerarse como con intención metodológica, no como una pura anécdota. El divino filósofo que consideraba que había una correspondencia geometría y proporcional entre algunas ideas y cosas sensibles, exigía también a sus discípulos que razonasen con el rigor de un geómetra. El ser puede ser definido en términos matemáticos y geométricos.

«Pues bien, aprende ahora que sitúe en el segundo segmento de la región inteligible aquello a que alcanza por sí misma la razón valiéndose del poder dialéctico y considerando la hipótesis no como principios, sino como verdaderas hipótesis, es decir, peldaños y trampolines que la elevan hasta lo no hipotético, hasta el principio de todo; $y$ una vez haya llegado a éste, irá pasando, de una a otra de las deducciones que de él dependen hasta que, de ese mòdo, (S).

10. PLATÓN, La República. Instituto de Estudios Pollticos. Madrid 1969, 510 b, Libro VI 
descienda a la conclusión sin recurrir en absoluto a nada sensible, antes bien, usando de las ideas tomadas en sí mismas, pasando de una a otra y terminando en las ideas" $)^{11}$.

Platón explica su concepción del ser y su metodología. Además del método geométrico, está el método dialéctico, que no tienen por qué ser contrapuesto. La visión del ser proporcionada por la dialéctica es más clara que la que proporcionan las artes.

En el Cratilo, al preguntar Sócrates por el filósofo dialéctico, se respondía que era el que poseía el arte de preguntar y de responder. Así la dialéctica tendría dos grandes ingredientes: la pregunta y la respuesta. El arte de preguntar tendría raíces socráticas y el arte de responder tendría aportaciones platónicas.

«Ahora aplícame a los cuatro segmentos estas cuatro operaciones que realiza el alma: la inteligencia (noesis), el más elevado; el pensamiento (dianoia), el segundo; al segundo dale la creencia (pistis) y al último la imaginación (eikasia); y ponles en orden, considerando que cada uno de ellos participa tanto más de la claridad cuanto más participen de la verdad los objetos a que se aplica»'12.

El Mito de la Caverna es la caja fuerte donde Platón guardó, con apariencia sencilla, las claves de su obra. La clave pedagógica, la clave política, la clave epistemológica, etc., están escondidas en las breves páginas de este mito. Del bien participan lo bello y lo recto, la verdad y el conocimiento; el bien es el sol que ilumina toda participación: — «Pues bien — dije-, esta imagen hay que aplicarla toda ella, joh amigo Glaucón!, a lo que se ha dicho antes; hay que comparar la vivienda prisión, y la luz del fuego que hay en ella, con el poder del sol. En cuanto a la subida del mundo de arriba y a la contemplación de las cosas de éste, si las comparas con la ascensión del alma hasta la región inteligible no errarás con respecto a mi vislumbre, que es lo que tú deseas conocer, y que sólo la divinidad sabe si por acaso está en lo cierto. En fin, he aquí lo que a mí me parece: en el mundo inteligible lo último que se percibe, y con trabajo, es la idea de bien, pero, una vez percibida, hay que colegir que ella es la causa de todo lo recto y lo bello que hay en todas las cosas; que, mientras en el mundo visible ha engendrado la luz y al soberano de ésta, en el inteligible es ella la soberana y la productora de verdad y conocimiento, y que tiene que verla por fuerza quien quiera proceder sabiamente en su vida privada y pública»s ${ }^{13}$.

11. PLATÓN, La República. Instituto de Estudios Políticos. Madrid 1969. 511 b-c, Libro VI (S).

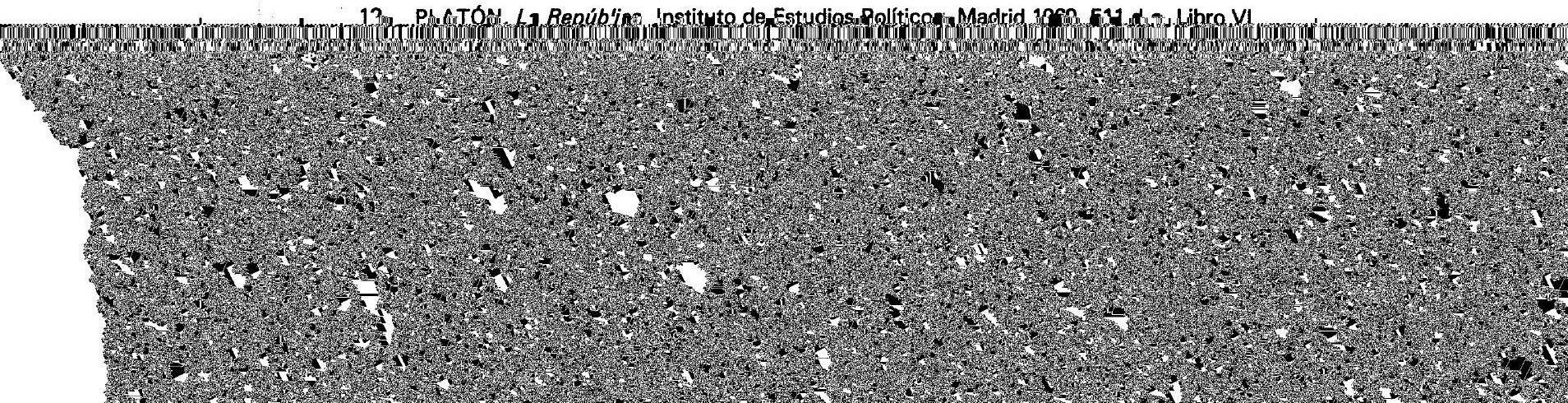


pueden distinguir y nos conducen a una apoteosis final. Los personajes se distribuyen de dos en dos para facilitar la expresión dialéctica y la disputa. El personaje Sócrates, que domina el resto de los diálogos de Platón, queda en éste en un lugar segundón, probablemente para realzar la figura de Parménides. Los temas tratados en este diálogo son de tal envergadura que parece que no quedan suficientemente aclarados y que el Parménides debe de continuar en otro $u$ otros diálogos.

Las relaciones entre el mundo sensible y el inteligible, así como la posibilidad de que el primero participe en el segundo, son abordadas también en el Teeteto o diálogo sobre la ciencia. Existen opiniones contrarias a este diálogo por considerar que ha contribuida al desprestigio de los sofistas. Los trabajos realizados en la Universidad de Valencia, bajo la dirección del profesor Montero, han devuelto a los sofistas su verdadero puesto. Parece que Platón no tiene la culpa de esa divinización de Sócrates y de esta mala fama de los sofistas, por lo menos, no tiene toda la culpa: - «¿Sabes acașo, Teodoro, qué es lo que más admiro de tu amigo Protágoras?

- Teodoro. - Dilo y lo sabré.

- Sócrates. - En muchos aspectos sus razones no me disgustan; así, por ejemplo, cuando muestra que lo que a cada uno parece, es, en ese sentido real. Pero el comienzo de su reflexión produjo en mí gran sorpresa. ¿No vino a decir, que «la medida de todas las cosas es el cerdo», o «el cinocéfalo», o cualquiera de esas bestias más insólitas que poseen sensación? ¡Y vaya manera presuntuosa y altisonante de comenzar su discurso! A todos los que le admirábamos como si fuese un dios por su sabiduría, no sólo nos demostró que no era superior por su juicio a cualquier hombre, sino que ni siquiera resultaba serlo con respecto a un simple renacuajo ${ }^{15}$.

Todo conocimiento empieza por los sentidos, pero no se queda en ellos, pues si así sucediese no se podría establecer la ciencia. El sensismo y relativismo sofista es para Platón un atentado contra la ciencia y contra su teoría de la participación, por eso, el autor de La República quiere cortar por lo sano, modificando, si es necesario, la doctrina de Protágoras. Protágoras decía que rel hombre era la medida de todas las cosas», Platón quiere hacerle decir que el cerdo era la medida de todas las cosas. Cada uno,diría Sto. Tomás, «recibe según la capacidad que tiene de recibir», y por lo tanto, un cierto relativismo no parece ser un mal tan ccndenable. Cada cosa participa de una forma el bien supremo, existe una proporcionalidad o relativismo respecto de la participación.

El Fedón apodado en la antigüedad "sobre el alma», trata de la inmortalidad de ésta, pero también esboza algunas teorías que después se estudiarán en La República: teoría de las ideas, teoría del conocimiento. Sócrates deja claro que es connatural al alma la participación de la inmortalidad. Critica las

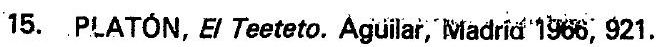


teorías de los fisicistas y también a Anaxágoras, que habla de una materia espiritual, pero que apenas recurre a ella cuando se trata de asegurar la inteligibilidad. Este espíritu material (nous) de Anaxágoras, ni forma parte del mundo de las ideas, ni es participado.

"Y es que la cuestión, Simmias, se nos presenta así»-continuó Sócrates - . Sí, como repetimos una y otra vez, existe lo bello, lo bueno y todo lo que es una realidad semejante, y a ella referimos todo lo que procede de las sensaciones, porque encontramos en ella algo que existía anteriormente $y$ nos pertenecía, es necesario que, de la misma manera que nuestras realidades existen, exista también nuestra alma, incluso antes de que nosotros naciéramos. Pero si éstas no existen, ¿no se habría dicho en vano este razonamiento? ¿No se presenta así la cuestión? ¿No hay una igual necesidad de que existan estas realidades y nuestra alma, antes, incluso, que nosotros naciéramos, y de que si no existen aquéllas tampoco existan éstas?

- Es extraordinaria, Sócrates, la impresión que tengo, dijo Simmias, de que hay la misma necesidad. $Y$ el razonamiento arriba a buen puerto, a saber: que nuestras almas existen antes de nacer nosotros, del mismo modo que la realidad de la que acabas de hablar. Pues nada tengo por tan evidente como el que lo bello, lo bueno y todas las demás cosas de esta índole de que hace un momento hablabas tienen existencia en grado sumo; $y$, en mi opinión, al menos, la demostración queda hecha de un modo satisfactorio ${ }^{16}$.

El Menón es un diálogo corto en el que Platón plantea el problema de la remiscencia y de las ideas innatas.

Mediante unas conversaciones con un esclavo, Sócrates demuestra que éste tiene en él ideas científicas, aún sin haber estudiado, y al preguntarle Sócrates, el esclavo las va recordando con toda exactitud.

Los ejemplos propuestos están tomados de la geometría, son deducibles lógicamente; comienzan en lo muy sencillo y llegan a un cierto grado de complicación.

El hecho de que el esclavo analfabeto conteste con corrección a las preguntas sobre geometría es suficiente para que Sócrates concluya que cuando nosotros aprendemos, en realidad sólo recordamos. Los sentidos y las preguntas son la ocasión para que tengamos reminiscencia de la sabiduría que nuestra alma tenía en el mundo de las ideas, sabiduría participada de la idea de bien.

- «Sócrates. - En estos momentos las opiniones verdaderas han brotado en él como en un sueño. Pero si se le interrogase con frecuencia y de diversas formas sobre los mismo temas, puedes estar seguro de que acabaría por tener de ellos un saber tan exacto como cualquiera.

- Menón. - Es probable.

- Sócrates. - Sabrás, pues, sin haber tenido maestro, gracias a simples

16. PLATÓN, El Fedón: Aguilar, Madrid 1966, 634-635. 
preguntas, habiendo vuelto a encontrar en sí mismo por sí mismo su ciencia, ¿no es así?

-Menón. - Sí.

- Sócrates. - Ahora bien: reencontrar por sí mismo y en sí mismo su sabiduría, ¿acaso no es precisamente recordar?

Menón. - Enteramente $)^{17}$.

Parece, pues, demostrado que se da la reminiscencia. Ahora bien, si se recuerda una determinada ciencia, como nadie da lo que no tiene, parece necesario que antes la hubiera aprendido o participado: « $Y$ no es necesario que esta ciencia que tiene él ahora, o bien la haya recibido en un momento determinado, o bien que la haya tenido siempre?

-Menón, -Sí.

- Sócrates. - Ahora bien, si siempre la ha tenido es porque siempre ha sido sabio, y si la ha recibido en un momento determinado, no habrá ocurrido esto seguramente en la presente vida. ¿Ha tenido él, pues, por causalidad un maestro en geometría? porque él reencontrará de la misma manera toda la geometría, así como todas las demás ciencias. ¿Acaso alguien se lo ha enseñado todo? Imagino que tú debes saberlo bien, y tanto mejor cuanto que ha nacido y se ha criado en tu casa.

- Menón. - Estoy completamente seguro de que nunca ha tenido un maestro» ${ }^{18}$.

No hay duda de que la demostración tiene una gran fuerza y que da aliento a las teorías aprioristas e innatistas. Parece que nacemos con unas estructuras mentales, o a menos con predisposición a adquirlas. ¿Cuándo nace en nosotros el concepto de verdad? ¿Qué principios de ética escribe la ley natural en nosotros? ¿Cuándo adquirimos las nociones de espacio y de tiempo? ¿Porqué el principio de contradicción es evidente para nosotros?

Parece que antes de toda experiencia poseemos ya un cierto número de ideas, o tenemos predisposición para poseerlas. ¿Quién puso en nosotros esas ideas innatas. Quién nos dejó predispuestos a discernir lo que es justo y lo que es injusto, aun antes de habérnoslo enseñado?

Es razonable no rechazar la doctrina de Platón sobre el innatismo, sin antes hacer una profunda reflexión sobre la misma.

Finalizaremos este estudio sobre la participación comentando unos textos de Las Leyes, escritos en la vejez de Platón.

Algunos críticos han despreciado estos últimos escritos alegando fallos estilísticos, incoherencias, etc. No nos parece justa esta postura, ni carecen de profundidad y de méritos las Leyes.

Sabemos con certeza que son los últimos escritos del genial maestro de Aristóteles, o por lo menos que los escribió cuando ya era muy viejo.

17. PLATÓN, El Menón. Aguilar, Madrid 1966, 455.

18. PLATÓN, El Menón. Aguilar, Madrid 1966, 455. 
Las Leyes deberían de ser estudiadas por un jurista más que por un filósofo. Sin embargo también tienen enseñanzas para estos últimos. El derecho, las leyes, emanan de las costumbres, de la ley natural y de la ideología, por tanto, justo es el estudiar lo que está detrás de la legislación.

No es un secreto para nadie que Platón deseó ardientemente participar en política, no sólo como ideólogo, sino como gobernante. La participación que tiene sus raíces en las ideas, tiene también manifestaciones socioculturales muy cercanas. Platón luchó políticamente contra la tiranía y encontró que el modo más eficaz de combatir la tiranía era la participación. Si los ciudadanos participan en la enseñanza, en la confección de las leyes, en la administración de la ciudad, poco espacio le queda al tirano, digamos que la tiranía desaparece automáticamente cuando cada uno participa desde su puesto en las cosas que le atañen y en aquellas de interés común. En el mito de la caverna nos lo explica con una gran claridad. Que nadie crea que los Estados nacen de las encinas y de las rosas, dice en el Libro octavo de La República. Los Estados, añade, nacen de los caracteres que poseen los hombres y de sus costumbres. El saber popular dice que cada país tiene el gobierno que se merece, y Platón vendría a darle la razón. Así pues, es misión del hombre el trabajar y participar en la lucha por la ciencia y en la lucha por los asuntos de la polis.

El alma es, después de los dioses lo más divino que hay: «pues de todos los bienes que uno tiene, el alma es, si se exceptúan los dioses, lo más divino que hay, y ello porque es también lo más personal. En efecto, todas las cosas que uno tiene pertenecen en todo humano a una de dos clases: la de lo mejor y superior, que es lo que rige, y la de lo peor o inferior, que es lo sometido a servidumbre; pues bien, hay que preferir siempre aquella parte de uno que manda a aquella otra que obedece ${ }^{19}$.

El alma participa del mundo de las ideas, el cuerpo sirve en el mundo de las sombras. Si mandase nuestro cuerpo sería el reino de las opiniones y de las sombras, un reino asentado sobre lo mudable y que no conoce ni la verdad, ni la justicia, ni la divinidad, porque como nos aconseja Platón: «No es posible que jamás llegue a ser un firme creyente en la divinidad ninguno de los hombres mortales que no pueda hacerse cargo de las dos cosas dichas ahora, QUE EL ALMA ES LO MÁS ANTIGUO DE TODO CUANTO PARTICIPA DE GENERACIÓN Y QUE ES INMORTAL Y GOBIERNA A LOS CUERPOS TODOS $\|^{20}$.

\section{ANTONIO NATAL Instituto Eijo y Garay Madrid 1978}

19. PLATON, Las Leyes. Texto bilingüe. Instituto de Estudios Políticos, Madrid 1970, 726 a, Libro V (E).

20. PLATÓN, Las Leyes. Instituto de Estudios Políticos, Madrid 1970, 968 a, Libro XII (IB). 
Las Leyes deberían de ser estudiadas por un jurista más que por un filósofo. Sin embargo también tienen enseñanzas para estos últimos. El derecho, las leyes, emanan de las costumbres, de la ley natural y de la ideología, por tanto, justo es el estudiar lo que está detrás de la legislación.

No es un secreto para nadie que Platón deseó ardientemente participar en política, no sólo como ideólogo, sino como gobernante. La participación que tiene sus raíces en las ideas, tiene también manifestaciones socioculturales muy cercanas. Platón luchó políticamente contra la tiranía y encontró que el modo más eficaz de combatir la tiranía era la participación. Si los ciudadanos participan en la enseñanza, en la confección de las leyes, en la administración de la ciudad, poco espacio le queda al tirano, digamos que la tiranía desaparece automáticamente cuando cada uno participa desde su puesto en las cosas que le atañen y en aquellas de interés común. En el mito de la caverna nos lo explica con una gran claridad. Que nadie crea que los Estados nacen de las encinas y de las rosas, dice en el Libro octavo de La República. Los Estados, añade, nacen de los caracteres que poseen los hombres y de sus costumbres. El saber popular dice que cada país tiene el gobierno que se merece, y Platón vendría a darle la razón. Así pues, es misión del hombre el trabajar y participar en la lucha por la ciencia y en la lucha por los asuntos de la polis.

El alma es, después de los dioses lo más divino que hay: «pues de todos los bienes que uno tiene, el alma es, si se exceptúan los dioses, lo más divino que hay, y ello porque es también lo más personal. En efecto, todas las cosas que uno tiene pertenecen en todo humano a una de dos clases: la de lo mejor y superior, que es lo que rige, y la de lo peor o inferior, que es lo sometido a servidumbre; pues bien, hay que preferir siempre aquella parte de uno que manda a aquella otra que obedece ${ }^{19}$.

El alma participa del mundo de las ideas, el cuerpo sirve en el mundo de las sombras. Si mandase nuestro cuerpo sería el reino de las opiniones y de las sombras, un reino asentado sobre lo mudable y que no conoce ni la verdad, ni la justicia, ni la divinidad, porque como nos aconseja Platón: «No es posible que jamás llegue a ser un firme creyente en la divinidad ninguno de los hombres mortales que no pueda hacerse cargo de las dos cosas dichas ahora, QUE EL ALMA ES LO MÁS ANTIGUO DE TODO CUANTO PARTICIPA DE GENERACIÓN Y QUE ES INMORTAL Y GOBIERNA A LOS CUERPOS TODOS $\|^{20}$.

\section{ANTONIO NATAL Instituto Eijo y Garay Madrid 1978}

19. PLATON, Las Leyes. Texto bilingüe. Instituto de Estudios Políticos, Madrid 1970, 726 a, Libro V (E).

20. PLATÓN, Las Leyes. Instituto de Estudios Políticos, Madrid 1970, 968 a, Libro XII (IB). 